\title{
Sensitization of Cervical Cancer Cells to Cisplatin by Genistein: The Role of NFkB and Akt/mTOR Signaling Pathways
}

\author{
K. Sahin, ${ }^{1}$ M. Tuzcu, ${ }^{2}$ N. Basak, ${ }^{3}$ B. Caglayan, ${ }^{4}$ U. Kilic, ${ }^{5}$ F. Sahin, ${ }^{3}$ and O. Kucuk ${ }^{6}$ \\ ${ }^{1}$ Department of Animal Nutrition, Faculty of Veterinary Medicine, Firat University, 23119 Elazig, Turkey \\ ${ }^{2}$ Department of Biology, Faculty of Science, Firat University, 23119 Elazig, Turkey \\ ${ }^{3}$ Department of Genetics and Bioengineering, Faculty of Engineering and Architecture, Yeditepe University, 34755 Istanbul, Turkey \\ ${ }^{4}$ Department of Physiology, Faculty of Medicine, Yeditepe University, 34755 Istanbul, Turkey \\ ${ }^{5}$ Department of Medical Biology, Faculty of Medicine, Bezmialem Vakif University, 34093 Istanbul, Turkey \\ ${ }^{6}$ Winship Cancer Institute, Emory University, Atlanta, GA 30322, USA
}

Correspondence should be addressed to O. Kucuk, okucuk@emory.edu

Received 16 July 2012; Accepted 22 August 2012

Academic Editor: Julian J. Raffoul

Copyright ( $\odot 2012$ K. Sahin et al. This is an open access article distributed under the Creative Commons Attribution License, which permits unrestricted use, distribution, and reproduction in any medium, provided the original work is properly cited.

\begin{abstract}
Cervical cancer is among the top causes of death from cancer in women. Cisplatin-based chemotherapy has been shown to improve survival; however, cisplatin treatment is associated with toxicity to healthy cells. Genistein has been used as an adjunct to chemotherapy to enhance the activity of chemotherapeutic agents without causing increased toxicity. The present study was designed to investigate the effect of genistein $(25 \mu \mathrm{M})$ on antitumor activity of cisplatin $(250 \mathrm{nM})$ on HeLa cervical cancer cells. We have examined the alterations in expression of NF- $\kappa$ B, p-mTOR, p-p70S6K1, p-4E-BP1, and p-Akt protein levels in response to treatment. The combination of $25 \mu \mathrm{M}$ genistein with $250 \mathrm{nM}$ cisplatin resulted in significantly greater growth inhibition $(P<0.01)$. Genistein enhanced the antitumor activity of cisplatin and reduced the expression of NF- $\kappa \mathrm{B}, \mathrm{p}-\mathrm{mTOR}$, p-p70S6K1, p-4E-BP1, and p-Akt. The results in the present study suggest that genistein could enhance the activity of cisplatin via inhibition of NF- $\kappa \mathrm{B}$ and Akt/mTOR pathways. Genistein is a promising nontoxic nutritional agent that may enhance treatment outcome in cervical cancer patients when given concomitantly with cisplatin. Clinical trials of genistein and cisplatin combination are warranted to test this hypothesis.
\end{abstract}

\section{Introduction}

As of 2008, cervical cancer is the third most common cause of cancer and the fourth most frequent cause of deaths from cancer in women and more than 500,000 new cervical cancer cases and 275,000 deaths were reported worldwide [1]. Although the high incidence rate is disappointing, survival rates of these patients continue to improve with the recent developments in the treatment of this particular cancer type $[1,2]$. As the number of studies investigating the application of chemotherapeutical agents as a concomitant treatment method increases, chemoradiotherapy including cisplatin is becoming the recommended method instead of radiotherapy alone [2].

Cisplatin (cis-diamminedichloroplatinum II, CDDP), is an effective agent in the treatment of cervical cancer [3]. However, its usage is limited by its toxicity and acquired chemoresistance throughout the course of treatment [4-6]. To this end, targeted therapies that can differentiate between tumor cells and healthy cells are being developed. A naturally occurring soybean isoflavone, genistein, could inhibit tumor growth and induce apoptosis of tumor cells without damaging the normal cells [7-9].

Genistein (4', 5,7-trihydroxyisoflavone) has a heterocyclic diphenolic structure that is similar to estrogen, but it has a more potent biological activity $[10,11]$. Genistein can inhibit tyrosine kinase and inhibit cancer cell proliferation in vivo and in vitro without causing toxicity to healthy cells [12]. Studies suggest that genistein can also regulate several signaling pathways in cancer cells and promote cancer cell death. Inhibition of Nuclear Factor-kappa B (NF- $\kappa \mathrm{B})$ and attenuation of Akt pathways by genistein have been shown in various cancer types [13-16]. NF- $\kappa$ B not only controls the expression of genes involved in survival and proliferation, 
but also plays a key role in apoptosis [17]. Moreover, NF$\kappa \mathrm{B}$ inhibition in tumor cells may result in increased activity of topoisomerase II inhibitors and, hence, this inhibition can be used in anticancer therapy [18].

Phosphatidylinositol 3-kinase (PI3K)/Akt pathway is one of the major growth-factor-induced pathways in tumorigenesis and malignant transformation $[19,20]$. Akt pathway activates many downstream signaling pathways responsible for both cell survival and apoptosis [21]. Mammalian target of rapamycin (mTOR) is one of the downstream serine/threonine kinases of PI3K/Akt pathway and regulates cell growth and survival and, thus, it is considered as a valid target for anticancer treatments [22]. mTOR can be either directly phosphorylation-activated by Akt or indirectly activated by Akt through the inhibition of tuberous sclerosis complex 1 and 2 (TSC1/2) and activation of Ras homologue-enriched in brain (Rheb) [23]. mTOR exists as TORC1 and TORC2 complexes. In TORC1 complex, it initiates translation by eukaryotic translation initiation factor (eIF4E) binding proteins (4EBP1) and by ribosomal p70S6 kinase (p70S6K). When mTOR protein phosphorylates $4 \mathrm{E}-\mathrm{BP} 1$, it dissociates from eIF4E. Once eIF4E is freed from 4e-BP1, it can form complex structures with several other proteins, including eIF4G or eIF4F. When mTOR phosphorylates p70S6K, this kinase phosphorylates S6 ribosomal protein in return [24, 25]. S6 kinase can catalyze phosphorylation and inhibition of insulin receptor substrate (IRS) proteins; then IRS proteins can no longer activate PI3K pathway and this results in an indirect inhibitory effect on Akt $[26,27]$. mTOR can also phosphorylate Akt through a possible positive feedback mechanism [28].

In this study, we hypothesized that cisplatin treatment administered together with genistein could potentiate cervical cancer growth inhibition in vitro through downregulation of mTOR pathway. To test our hypothesis, we evaluated the effects of genistein and cisplatin on cell growth and apoptosis-related gene expression in HeLa human cervical cancer cell line.

\section{Materials and Methods}

2.1. Cell Culture and Reagents. The human cervical cancer cell line, HeLa cells (American Type Culture Collection, Manassas, VA) was maintained in RPMI-1640 medium containing $10 \%$ heat inactivated fetal bovine serum, $1 \% \mathrm{~L}$ glutamine, $100 \mathrm{U} / \mathrm{mL}$ penicillin $\mathrm{G}$, and $100 \mu \mathrm{g} / \mathrm{mL}$ streptomycin. Cells were incubated in a humidified, 5\% $\mathrm{CO}_{2}$ atmosphere at $37^{\circ} \mathrm{C}$. No growth factors were added to the cell culture medium at any time. Genistein (Sigma Chemical Co., St. Louis, MO, USA) was dissolved in $0.1 \mathrm{M} \mathrm{Na}_{2} \mathrm{CO}_{3}$ to make a $10-\mathrm{mM}$ stock solution. Cisplatin (Sigma Chemical Company, St. Louis, MO) was dissolved in phosphate buffered saline (PBS) to make a $0.5 \mathrm{mM}$ stock solution.

2.2. Cell Viability Assay. Cell viability was determined by MTS Assays. HeLa cells were seeded 3000 cells in a 96well plate and incubated overnight. Cells $\left(2-5 \times 10^{4}\right)$ were treated with genistein $(25 \mu \mathrm{M})$, cisplatin $(250 \mathrm{nM})$, and their combination treatment for 24 hours. After 24 hours of total treatment, the cells were incubated at $37^{\circ} \mathrm{C}$ with $1 \mathrm{mg} / \mathrm{mL}$ MTT reagent (Sigma, St. Louis, MO) for 2 hours. The formazan crystals were dissolved in isopropanol. Spectrophotometric absorbance of the samples was determined by the ULTRA Multifunctional Microplate Reader (ELx800BIO-TEK) at $490 \mathrm{~nm}$.

2.3. Western Blot Analysis. HeLa cells were treated with genistein $(25 \mu \mathrm{M})$, cisplatin $(250 \mathrm{nM})$, and the combination treatment for 24 hours. The total proteins from these samples were extracted. These total proteins were resolved through sodium dodecyl sulfate polyacrylamide gels and then were transferred to a nitrocellulose membrane. After blocking with $5 \%$ nonfat dry milk, the membrane was incubated with anti-NF- $\kappa$ B p65, anti-mTOR, anti-70S6K1, anti-4EBP1, and anti-Akt (Abcam, Cambridge, UK). Primary antibody was diluted $(1: 1000)$ in the same buffer containing $0.05 \%$ Tween-20. The nitrocellulose membrane was incubated overnight at $4{ }^{\circ} \mathrm{C}$ with protein antibody. The blots were washed and incubated with horseradish peroxidaseconjugated goat anti-mouse IgG (Abcam, Cambridge, UK). Specific binding was detected using diaminobenzidine and $\mathrm{H}_{2} \mathrm{O}_{2}$ as substrates. Protein loading was controlled using a monoclonal mouse antibody against $\beta$-actin antibody (A5316; Sigma). Blots were performed at least three times to confirm data reproducibility. Bands were analyzed densitometrically using an image analysis system (Image J; National Institute of Health, Bethesda, USA).

2.4. Statistical Analysis. To determine the difference in cell viability between experimental sets of cervical cancer cell line, experiments were repeated at least three times and SPSS was used for statistical analysis. Comparisons of treatment outcome were tested for statistical difference by the paired $t$ test. Statistical significance was assumed at a $P$ value of $<0.05$.

\section{Results}

3.1. Genistein Enhances the Inhibitory Effect of Cisplatin on the Proliferation of HeLa Cells. The effects of genistein, cisplatin, and their combination on the proliferation of HeLa cells were evaluated with MTS assay. In MTS assay, cells are treated with a tetrazolium compound, MTS (3-[4,5-dimethylthiazol-2yl]-2,5-diphenyltetrazolium bromide). Since metabolically active cells can reduce MTS to insoluble purple formazan dye products, relative cell viability for each treatment compared to control was measured [29]. Data from this assay showed that combination treatment of genistein and cisplatin enhances the inhibition of cellular growth in HeLa cells.

The rationale for choosing $250 \mathrm{nM}$ cisplatin and $25 \mu \mathrm{M}$ genistein came from our previous observation that revealed a marked inhibition of cell growth in human cancer cells [7]. HeLa cells were treated with cisplatin and genistein alone and in combination of the two for 24 hours. When compared to controls, combination treatment inhibited the proliferation of HeLa cells to significantly higher extend than either treatment alone. Percent of viable cells after the combination treatment decreased to $\sim 30 \%$, while percents of viable cells for genistein treatment alone and for cisplatin treatment 


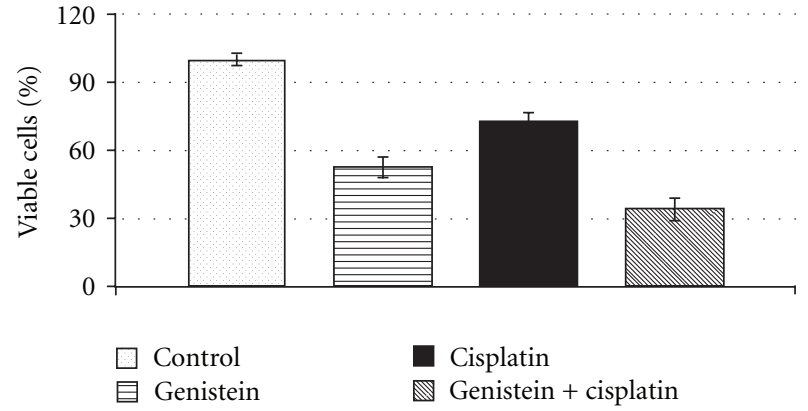

FIGURE 1: Growth inhibition of human cervical cancer cell lines HeLa treated with genistein, cisplatin, and the combination treatments were evaluated by the MTT assay. HeLa cells were treated with genistein $(25 \mu \mathrm{M})$, cisplatin $(250 \mathrm{nM})$, and the combination treatment. ${ }^{*} P<0.05$; ${ }^{*} P<0.01$.

alone were $\sim 50 \%$ and $\sim 70 \%$, respectively (Figure 1 ). These results suggest that combination of genistein with cisplatin elicited significantly greater growth inhibition in HeLa cells compared to either agent alone. Since we found that genistein could potentiate the inhibition of cancer cell growth, we next tested the expression of possible target proteins which may be involved in the mechanism of genistein and cisplatin.

3.2. Genistein Prevents Cisplatin-Induced Upregulation of NF$\kappa \mathrm{B}$ in $\mathrm{HeLa}$ Cells. NF- $\kappa \mathrm{B}$ is a transcription factor which plays an important role in apoptosis mechanisms by exerting its regulatory effects on survival genes. Expression level of NF- $\kappa \mathrm{B}$ was evaluated at the protein level. By Western Blot analysis, we examined the expression level of NF- $\kappa \mathrm{B}$ p $65 \mathrm{~B}$, a subunit of NF- $\kappa \mathrm{B}$ transcription complex, in genistein alone, cisplatin alone, and genistein-plus-cisplatin-treated HeLa cells. Cisplatin alone increased the expression level of NF- $\kappa \mathrm{B}$ p65B up to $150 \%$, compared to control, whereas genistein downregulated this subunit to $\sim 75 \%$. When genistein is added to cisplatin treatment, expression level of NF- $\kappa \mathrm{B}$ p $65 \mathrm{~B}$ protein is reduced to $\sim 80 \%$. These results suggest that genistein can downregulate the increased expression level of NF- $\kappa$ B induced by cisplatin in HeLa cells (Figure 2(a)).

\subsection{Genistein Inhibits Cisplatin-Induced Activation of mTOR} Pathway in HeLa Cells. In order to evaluate the involvement of mTOR molecular pathway in the antiproliferative effect of cisplatin and genistein, we assessed the expression levels of p-mTOR, p-p70S6K1, p-4E-BP1, and p-Akt in HeLa cells treated with genistein and/or cisplatin. Genistein reduced the level of phosphorylated mTOR, p70S6K1, 4e-BP1, and Akt induced by cisplatin in HeLa cells (Figures 2(b), 2(c), $2(\mathrm{~d})$, and $2(\mathrm{e}))$. mTOR is known to regulate initiation of translation through two pathways: S6K and 4E-BP1. As a decrease in expression of mTOR would cause a decrease in expression of these two molecules, this hypothesis is supported by our data.

\section{Discussion}

There is a need to develop more efficient treatment strategies to increase the efficacy of existing therapies while not compromising the normal cells. Cisplatin is one of the most effective anticancer agents in the treatment of cervical cancer; however, it is associated with severe toxicity and acquired drug resistance after therapy. Severe renal, neurologic, and gastrointestinal side effects and acquired chemoresistance are the major reasons of cisplatin treatment failure. To overcome the limitations of cisplatin treatment, combination with targeted therapy using naturally occurring compounds was suggested [30-32]. Many natural compounds with known anticancer activity have been used including sulforaphane $[33,34]$ and genistein [35]. In the light of these previous studies we chose genistein as a nontoxic nutritional agent to augment the efficacy of cisplatin treatment in HeLa cells.

In this study, we observed the superiority of genistein plus cisplatin combination compared to cisplatin alone in inhibition of the growth of HeLa cervical cancer cells in vitro. The effect of genistein on cisplatin's anticancer activity has been previously reported for ovarian cancer [36] and pancreatic cancer [35]. We investigated the therapeutic effect of genistein and cisplatin in the HeLa cells and found a statistically significant inhibition of cell growth when cells were treated with a combination of genistein and cisplatin, compared to either agent alone. Growth inhibition of HeLa by cisplatin was augmented by genistein, thereby obviating the need to further increase the concentration of cisplatin. The effect of genistein-mediated enhanced efficacy of cisplatin in cervical cancer cells was demonstrated for the first time in this study.

Activation of mTOR signaling pathway is associated with cell survival in cervical cancer cells [37]. We have found increased mTOR expression after cisplatin treatment which could be prevented by the addition of genistein, a mechanism first shown in the present study. The combination of cisplatin and genistein could be a promising strategy in the treatment of cervical cancer. mTOR activity can be monitored by phosphorylation of S6K, 4E-PB1 proteins [38]; we also observed increased expression of these proteins with cisplatin treatment which could be abrogated by genistein. When HeLa cells were treated with cisplatin alone, the expression levels of phosphorylated mTOR, p70S6K1, and 4E-BP1 increased up to $140 \%, 170 \%$, and $150 \%$, respectively. However, addition of genistein downregulated these cisplatin-induced proteins by $70 \%$. These results suggest that cisplatin upregulates mTOR pathway and genistein prevents this upregulation by downregulating phosphorylated p70S6K1 and 4E-BP1 proteins. We also observed that this activity is associated with downregulation of phosphorylated Akt, which suggests that decrease in the expression of mTOR pathway is probably mediated via Akt or a decrease in this pathway negatively regulates and inactivates Akt.

In this study, we also investigated the effects of genistein and cisplatin on NF- $\kappa \mathrm{B}$, which is known to be upregulated upon cisplatin treatment [36]. Similar to previous observations, genistein decreased the expression of cisplatin-induced $\mathrm{NF}-\kappa \mathrm{B}$ in HeLa cells. These results suggest a molecular mechanism involving both NF- $\kappa \mathrm{B}$ and mTOR pathways induced by cisplatin and inhibited by genistein. 

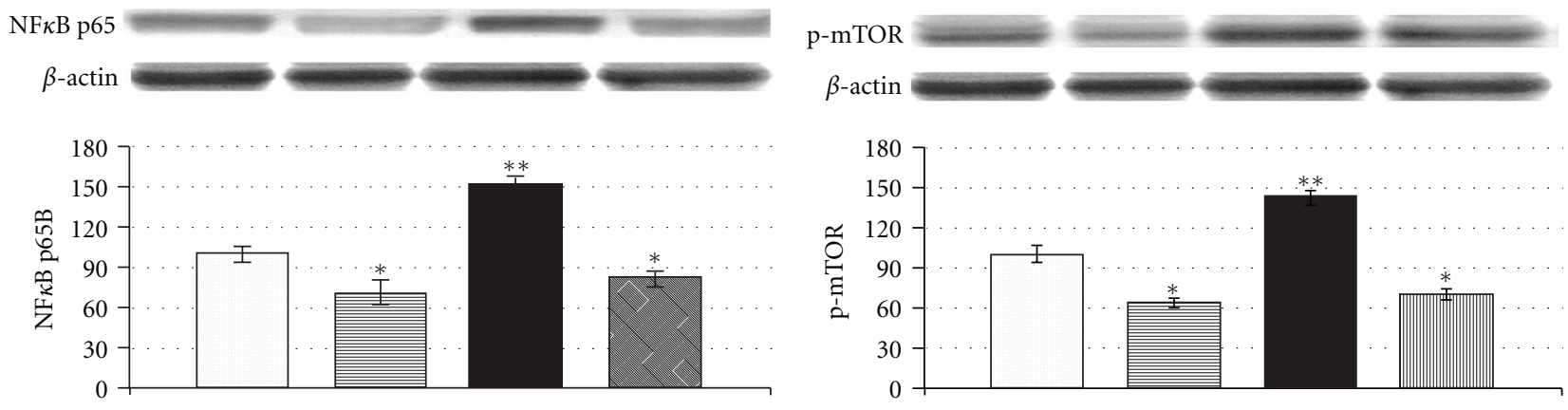

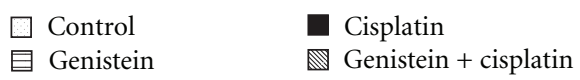

(a)
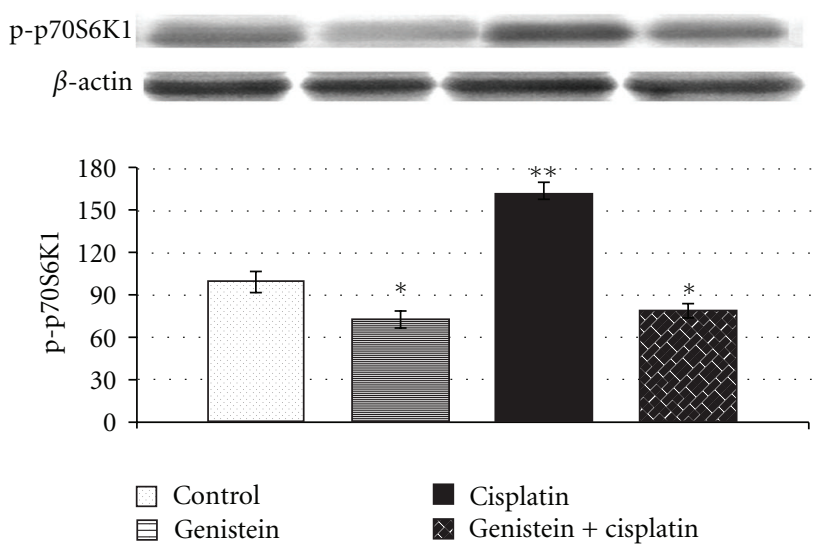

(c)

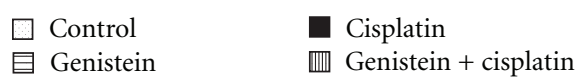

(b)
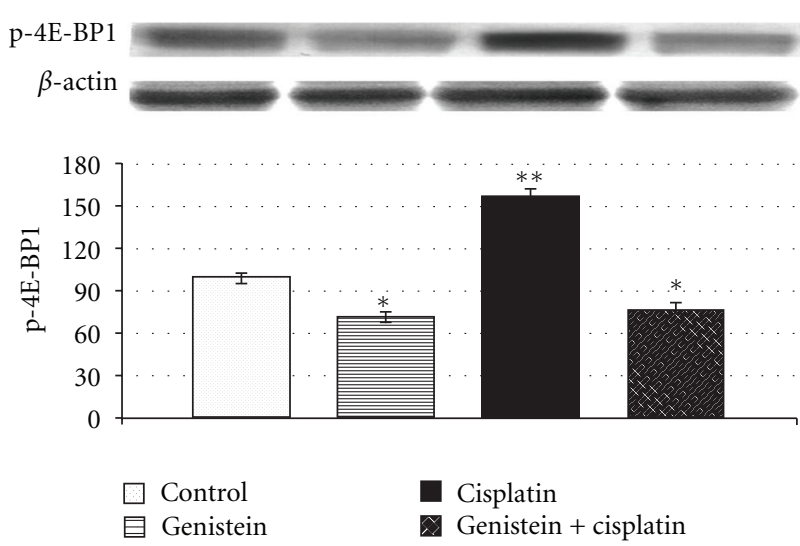

(d)

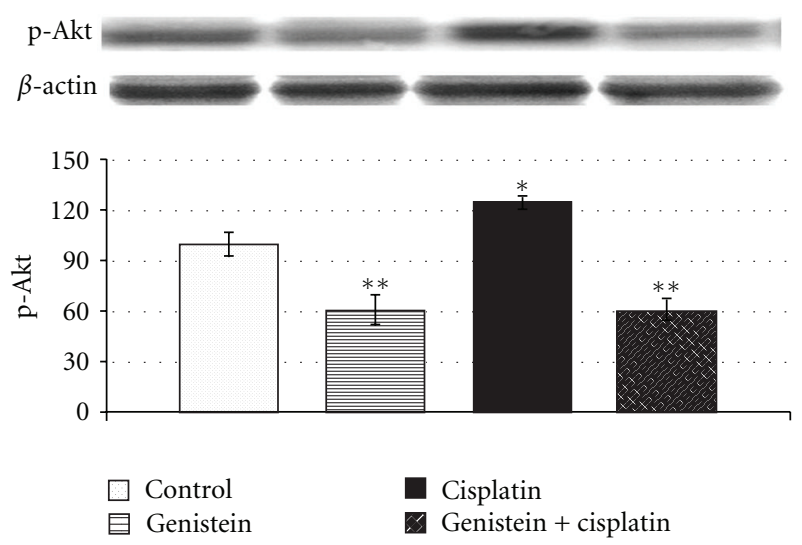

(e)

FIGURE 2: The intensity of the bands was quantified by the densitometric analysis. The expression of (a) NF- $\kappa \mathrm{B},(\mathrm{b}) \mathrm{p}-\mathrm{mTOR}$, (c) p-p70S6K1, (d) p-4E-BP1, and (e) p-Akt in HeLa cells. Cells untreated or treated with $25 \mu \mathrm{M}$ genistein, $250 \mathrm{nM}$ cisplatin (Cis), and the combination (genistein + cisplatin). $\beta$-actin antibodies were used as internal controls for equal loading of proteins. Data are percent of the control. ${ }^{*} P<$ $0.05 ; * *<0.01$.

\section{Conclusion}

In conclusion, cisplatin treatment is potentiated with genistein in HeLa cells by regulating NF- $\kappa \mathrm{B}$, Akt, and mTOR pathways which are critical for cell survival and apoptosis. Our findings suggest that cisplatin and genistein combination could be used to improve the treatment outcome in cervical cancer. This combination is a less toxic option in the treatment of cervical cancer, especially in the presence of chemoresistance to cisplatin. Future clinical trials are warranted to investigate the combination of cisplatin and genistein in patients with cervical cancer. 


\section{Conflict of Interests}

The authors have declared no conflict of interests.

\section{Acknowledgment}

O. Kucuk is a Georgia Cancer Coalition Distinguished Cancer Scholar.

\section{References}

[1] J. Ferlay, H. R. Shin, F. Bray, D. Forman, C. D. Mathers, and D. Parkin, "GLOBOCAN 2008, Cancer Incidence and Mortality Worldwide: IARC CancerBase No. 10,” International Agency for Research on Cancer, Lyon, France, 2010, http://globocan.iarc.fr/.

[2] V. M. K. Bhavaraju, N. S. Reed, and T. Habeshaw, "Acute toxicity of concomitant treatment of chemoradiation of single agent cisplatin in patients with carcinoma of cervix," Thai Journal of Physiological Sciences, vol. 17, pp. 90-97, 2004.

[3] F. Muggia, "Platinum compounds 30 years after the introduction of cisplatin: implications for the treatment of ovarian cancer," Gynecologic Oncology, vol. 112, no. 1, pp. 275-281, 2009.

[4] P. J. Loehrer and L. H. Einhorn, "Drugs five years later: cisplatin," Annals of Internal Medicine, vol. 100, no. 5, pp. 704713, 1984.

[5] J. Reedijk, "New clues for platinum antitumor chemistry: kinetically controlled metal binding to DNA," Proceedings of the National Academy of Sciences of the United States of America, vol. 100, no. 7, pp. 3611-3616, 2003.

[6] K. Woźniak and J. Błasiak, "Recognition and repair of DNAcisplatin adducts," Acta Biochimica Polonica, vol. 49, no. 3, pp. 583-596, 2002.

[7] Y. Li, F. Ahmed, S. Ali, P. A. Philip, O. Kucuk, and F. H. Sarkar, "Inactivation of nuclear factor $\kappa \mathrm{B}$ by soy isoflavone genistein contributes to increased apoptosis induced by chemotherapeutic agents in human cancer cells," Cancer Research, vol. 65, no. 15, pp. 6934-6942, 2005.

[8] J. A. Ross and C. M. Kasum, "Dietary flavonoids: bioavailability, metabolic effects, and safety," Annual Review of Nutrition, vol. 22, pp. 19-34, 2002.

[9] F. H. Sarkar and Y. Li, "Mechanisms of cancer chemoprevention by soy isoflavone genistein," Cancer and Metastasis Reviews, vol. 21, no. 3-4, pp. 265-280, 2002.

[10] T. Akiyama, J. Ishida, S. Nakagawa et al., "Genistein, a specific inhibitor of tyrosine-specific protein kinases," Journal of Biological Chemistry, vol. 262, no. 12, pp. 5592-5595, 1987.

[11] G. G. Hillman, Y. Wang, O. Kucuk et al., "Genistein potentiates inhibition of tumor growth by radiation in a prostate cancer orthotopic model," Molecular Cancer Therapeutics, vol. 3, no. 10, pp. 1271-1279, 2004.

[12] S. Barnes, "Effect of genistein on in vitro and in vivo models of cancer," Journal of Nutrition, vol. 125, no. 3, pp. 777S-783S, 1995.

[13] J. N. Davis, B. Singh, M. Bhuiyan, and F. H. Sarkar, "Genisteininduced upregulation of $\mathrm{p} 21$ (WAFI), downregulation of cyclin $\mathrm{B}$, and induction of apoptosis in prostate cancer cells," Nutrition and Cancer, vol. 32, no. 3, pp. 123-131, 1998.

[14] J. N. Davis, O. Kucuk, and F. H. Sarkar, "Genistein inhibits NF$\kappa \mathrm{B}$ activation in prostate cancer cells," Nutrition and Cancer, vol. 35, no. 2, pp. 167-174, 1999.
[15] Y. Li, S. Upadhyay, M. Bhuiyan, and F. H. Sarkar, "Induction of apoptosis in breast cancer cells MDA-MB-231 by genistein," Oncogene, vol. 18, no. 20, pp. 3166-3172, 1999.

[16] Y. Li and F. H. Sarkar, "Inhibition of nuclear factor $\kappa \mathrm{B}$ activation in PC3 cells by genistein is mediated via Akt signaling pathway," Clinical Cancer Research, vol. 8, no. 7, pp. 2369-2377, 2002.

[17] B. F. El-Rayes, S. Ali, I. F. Ali, P. A. Philip, J. Abbruzzese, and F. H. Sarkar, "Potentiation of the effect of erlotinib by genistein in pancreatic cancer: the role of Akt and nuclear factor- $\kappa \mathrm{B}$," Cancer Research, vol. 66, no. 21, pp. 10553-10559, 2006.

[18] Z. P. Lin, Y. C. Boiler, S. M. Amer et al., "Prevention of Brefeldin A-induced resistance to teniposide by the proteasome inhibitor MG-132: involvement of NF- $\kappa$ B activation in drug resistance," Cancer Research, vol. 58, no. 14, pp. 30593065, 1998.

[19] I. Vivanco and C. L. Sawyers, "The phosphatidylinositol 3-kinase-AKT pathway in human cancer," Nature Reviews Cancer, vol. 2, no. 7, pp. 489-501, 2002.

[20] A. J. Wong, S. H. Bigner, D. D. Bigner, K. W. Kinzler, S. R. Hamilton, and B. Vogelstein, "Increased expression of the epidermal growth factor receptor gene in malignant gliomas is invariably associated with gene amplification," Proceedings of the National Academy of Sciences of the United States of America, vol. 84, no. 19, pp. 6899-6903, 1987.

[21] J. Q. Cheng and S. V. Nicosia, "Akt signal transduction pathway in oncogenesis," in Encylopedia Reference of Cancer, pp. 35-37, Springer, Berlin, Germany, 2001.

[22] N. Hay and N. Sonenberg, "Upstream and downstream of mTOR," Genes and Development, vol. 18, no. 16, pp. 19261945, 2004.

[23] F. Kaper, N. Dornhoefer, and A. J. Giaccia, "Mutations in the PI3K/PTEN/TSC2 pathway contribute to mammalian target of rapamycin activity and increased translation under hypoxic conditions," Cancer Research, vol. 66, no. 3, pp. 1561-1569, 2006.

[24] M. A. Bjornsti and P. J. Houghton, "The TOR pathway: a target for cancer therapy," Nature Reviews Cancer, vol. 4, no. 5, pp. 335-348, 2004.

[25] M. Hidalgo and E. K. Rowinsky, "The rapamycin-sensitive signal transduction pathway as a target for cancer therapy," Oncogene, vol. 19, no. 56, pp. 6680-6686, 2000.

[26] O. J. Shah, Z. Wang, and T. Hunter, "Inappropriate activation of the TSC/Rheb/mTOR/S6K cassette induces IRS1/2 depletion, insulin resistance, and cell survival deficiencies," Current Biology, vol. 14, no. 18, pp. 1650-1656, 2004.

[27] L. S. Harrington, G. M. Findlay, A. Gray et al., "The TSC1-2 tumor suppressor controls insulin-PI3K signaling via regulation of IRS proteins," Journal of Cell Biology, vol. 166, no. 2, pp. 213-223, 2004.

[28] D. D. Sarbassov, D. A. Guertin, S. M. Ali, and D. M. Sabatini, "Phosphorylation and regulation of Akt/PKB by the rictormTOR complex," Science, vol. 307, no. 5712, pp. 1098-1101, 2005.

[29] F. Denizot and R. Lang, "Rapid colorimetric assay for cell growth and survival - Modifications to the tetrazolium dye procedure giving improved sensitivity and reliability," Journal of Immunological Methods, vol. 89, no. 2, pp. 271-277, 1986.

[30] F. H. Sarkar and Y. Li, "Using chemopreventive agents to enhance the efficacy of cancer therapy," Cancer Research, vol. 66, no. 7, pp. 3347-3350, 2006.

[31] S. P. Ermakova, B. S. Kang, B. Y. Choi et al., “(-)-Epigallocatechin gallate overcomes resistance to etoposide-induced cell death by targeting the molecular chaperone glucose-regulated 
protein 78," Cancer Research, vol. 66, no. 18, pp. 9260-9269, 2006.

[32] A. K. Tyagi, C. Agarwal, D. C. Chan, and R. Agarwal, "Synergistic anti-cancer effects of silibinin with conventional cytotoxic agents doxorubicin, cisplatin and carboplatin against human breast carcinoma MCF-7 and MDA-MB468 cells," Oncology Reports, vol. 11, no. 2, pp. 493-499, 2004.

[33] H. Kim, E. H. Kim, Y. W. Eom et al., "Sulforaphane sensitizes tumor necrosis factor-related apoptosis-inducing ligand (TRAIL)-resistant hepatoma cells to TRAIL-induced apoptosis through reactive oxygen species-mediated up-regulation of DR5," Cancer Research, vol. 66, no. 3, pp. 1740-1750, 2006.

[34] G. Kallifatidis, S. Labsch, V. Rausch et al., "Sulforaphane increases drug-mediated cytotoxicity toward cancer stem-like cells of pancreas and prostate," Molecular Therapy, vol. 19, no. 1, pp. 188-195, 2011.

[35] S. Banerjee, Y. Zhang, Z. Wang et al., "In vitro and in vivo molecular evidence of genistein action in augmenting the efficacy of cisplatin in pancreatic cancer," International Journal of Cancer, vol. 120, no. 4, pp. 906-917, 2007.

[36] S. A. Solomon, S. Ali, S. Banerjee, A. R. Munkarah, R. T. Morris, and F. H. Sarkar, "Sensitization of ovarian cancer cells to cisplatin by genistein: the role of NF-kB," Journal of Ovarian Research, vol. 1, no. 1, p. 9, 2008.

[37] J. Ji and P. S. Zheng, "Activation of mTOR signaling pathway contributes to survival of cervical cancer cells," Gynecologic Oncology, vol. 117, no. 1, pp. 103-108, 2010.

[38] S. Menon and B. D. Manning, "Common corruption of the mTOR signaling network in human tumors," Oncogene, vol. 27, no. 2, supplement, pp. S43-S51, 2008. 


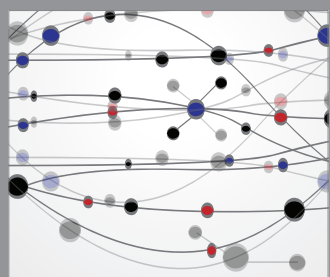

The Scientific World Journal
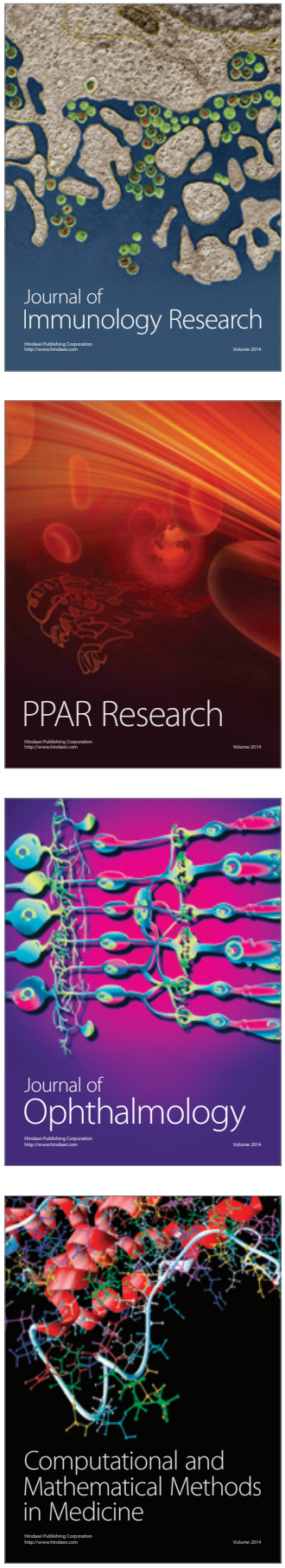

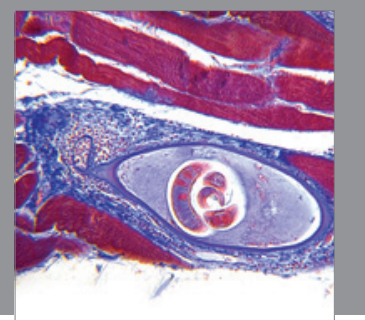

Gastroenterology

Research and Practice
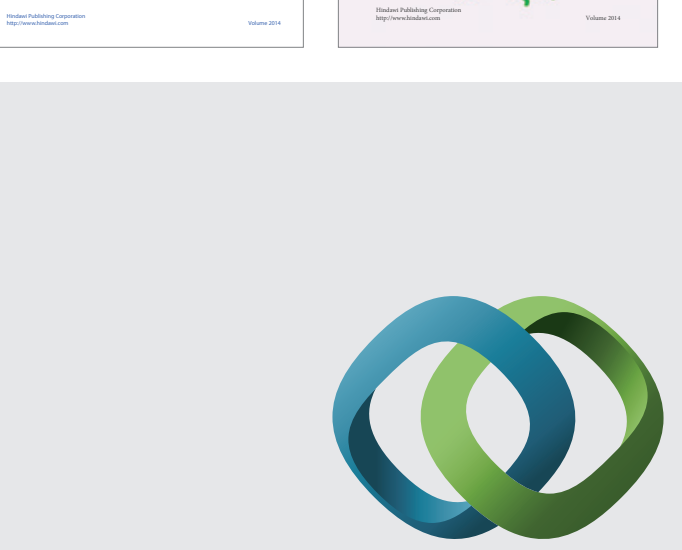

\section{Hindawi}

Submit your manuscripts at

http://www.hindawi.com
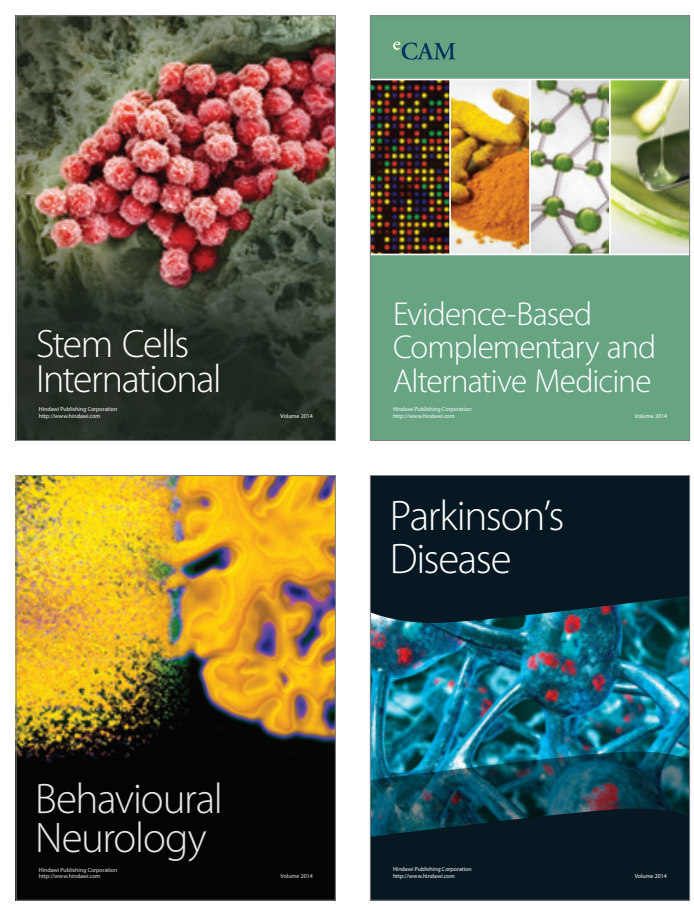

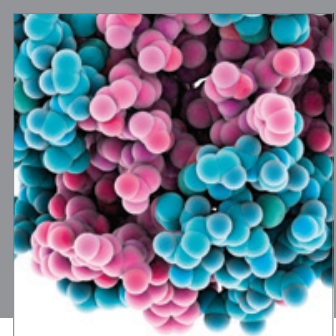

Journal of
Diabetes Research

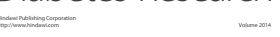

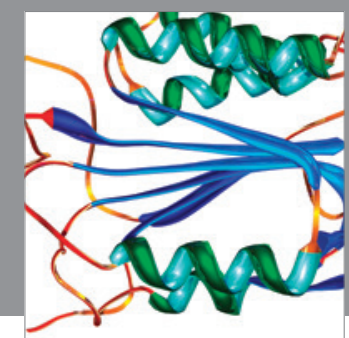

Disease Markers
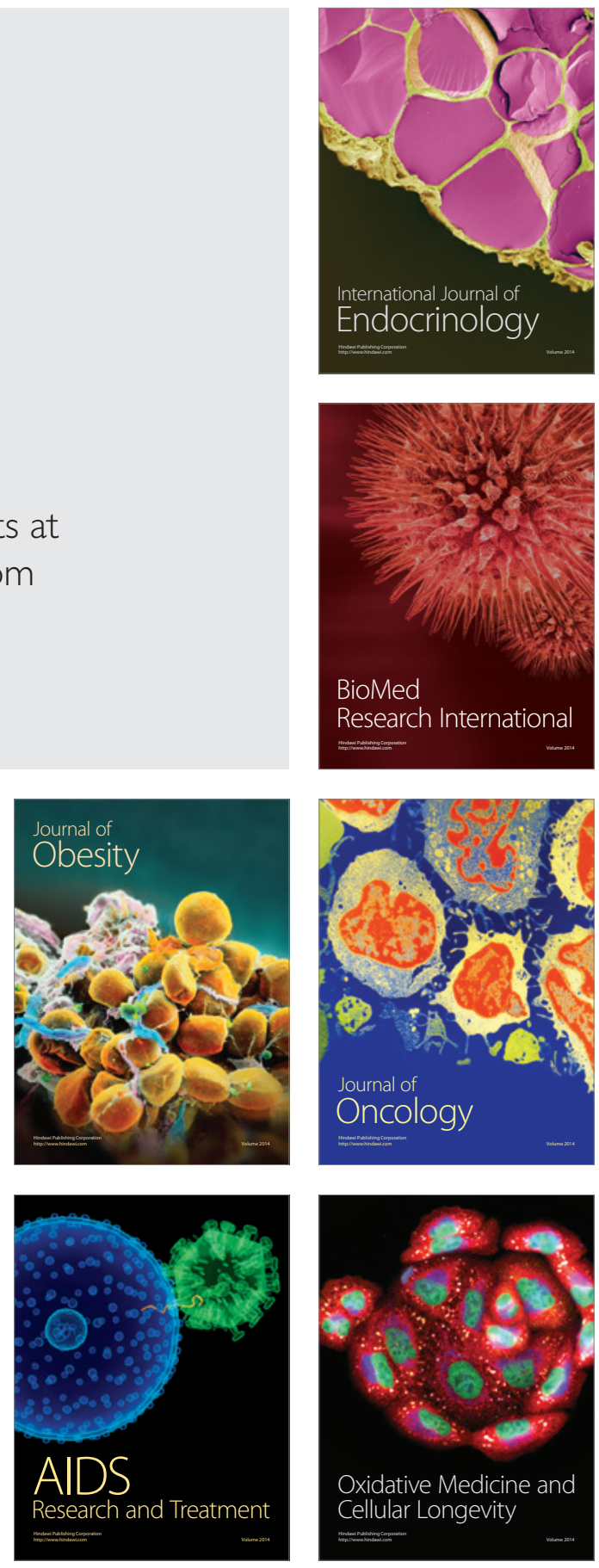